University of Louisville ThinkIR: The University of Louisville's Institutional Repository

Electronic Theses and Dissertations

$12-2015$

\title{
Educational excellence through dual degrees : using Symbolic Convergence Theory to make it happen here.
}

Stephanie Ann French

University of Louisville

Follow this and additional works at: https://ir.library.louisville.edu/etd

Part of the Organizational Communication Commons

\section{Recommended Citation}

French, Stephanie Ann, "Educational excellence through dual degrees : using Symbolic Convergence Theory to make it happen here." (2015). Electronic Theses and Dissertations. Paper 2291.

https://doi.org/10.18297/etd/2291

This Master's Thesis is brought to you for free and open access by ThinkIR: The University of Louisville's Institutional Repository. It has been accepted for inclusion in Electronic Theses and Dissertations by an authorized administrator of ThinkIR: The University of Louisville's Institutional Repository. This title appears here courtesy of the author, who has retained all other copyrights. For more information, please contact thinkir@louisville.edu. 
EDUCATIONAL EXCELLENCE THROUGH DUAL DEGREES: USING SYMBOLIC CONVERGENCE THEORY TO MAKE IT HAPPEN HERE

By

Stephanie Ann French

B.A., Jacksonville University, 1993

\author{
A Thesis \\ Submitted to the Faculty of the \\ College of Arts and Sciences of the University of Louisville \\ in Partial Fulfillment of the Requirements \\ for the Degree of
}

Master of Arts in Communication

Department of Communication

University of Louisville

Louisville, Kentucky

December 2015 
Copyright 2015 by Stephanie Ann French

All Rights Reserved 

EDUCATIONAL EXCELLENCE THROUGH DUAL DEGREES: USING

SYMBOLIC CONVERGENCE THEORY TO MAKE IT HAPPEN HERE

\section{By}

Stephanie Ann French

B.A., Jacksonville University, 1993

A Thesis Approved on

November 30, 2015

by the following Thesis Committee:

Allan Futrell, Ph.D.

Karen Freberg, Ph.D.

T. Christopher Greenwell, Ph.D. 


\section{DEDICATION}

This thesis is dedicated to my husband, Daniel H. French and our children,

Alexandra K. and Andrew B.

As well as my parents

Debra A. Culbertson and Norman G. Culbertson

Who have all supported and encouraged me through this journey.

And to, my mother and father-in-law, my greatest cheerleaders,

Patricia L. French and David F. French 


\section{ACKNOWLEDGMENTS}

First and foremost, I would like to thank the Communication Department Chair, Dr. Allan Futrell for having the confidence in me to pursue a thesis and providing his support along the way. I would also like to thank my other committee members, Dr. Karen Freberg and Dr. Chris Greenwell for their encouragement and guidance. Special notes to Dr. Robert N. St. Clair for being there when I needed faculty support and to Dr. John Ferré for sharing his wisdom and always conveying he cared even when I was no longer his student. I would also like to thank Courtney Kerr in the School of Interdisciplinary and Graduate Studies for her assistance and patience. 


\begin{abstract}
EDUCATIONAL EXCELLENCE THROUGH DUAL DEGREES: USING SYMBOLIC CONVERGENCE THEORY TO MAKE IT HAPPEN HERE Stephanie Ann French
\end{abstract}

November 30, 2015

Interdisciplinary studies is a goal for the University of Louisville as it pertains to the Vision 2020 Plan. Implementing interdisciplinary studies is a part of Educational Excellence, goal number one of five strategic goals in the Vision 2020. Each of the colleges at the university has devised a strategic plan to determine how each will contribute to that goal.

This specific research provides an overview of various issues pertaining to implementing programs in interdisciplinary studies. It then explores a specific instance of interdisciplinary possibilities by focusing on a single instance of what might become an exemplar of interdisciplinary studies. Specifically, it assesses the feasibility of creating a joint degree program between the departments of Sport Administration and Communication. Unlike previous analyses of potential interdisciplinary partners, however, this project takes a communicative perspective.

The Symbolic Convergence Theory, sometimes referred to as Fantasy Theme Analysis, serves as the underlying theoretical framework for analyzing the processes, messaging, and collaboration needed to create the common vision that can enable these 
two disciplines to mesh. Part and parcel of the approach is the nature of the data, which in this case consists of comments made during a focus group with current students from the two departments. Student comments, combined with educational and pedagogical research based insight, make for a unique method for establishing an interdisciplinary program. 
TABLE OF CONTENTS

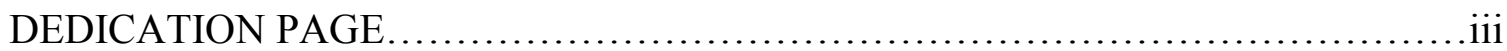

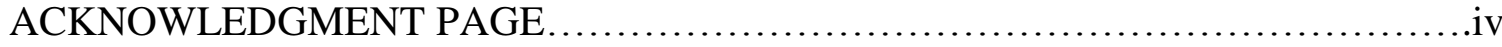

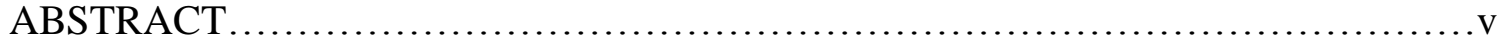

INTRODUCTION

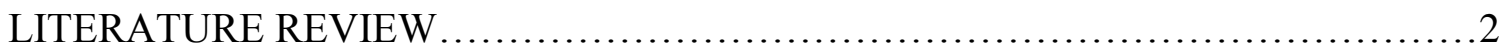

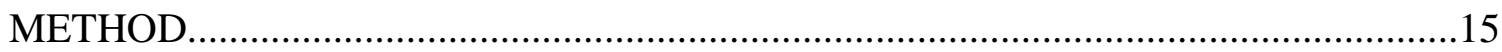

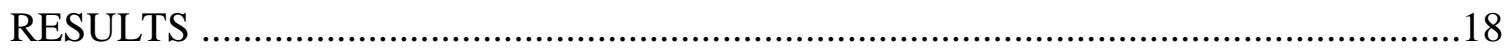

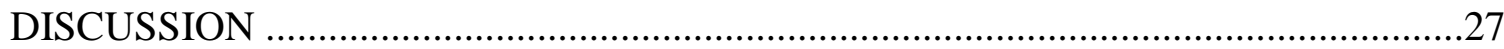

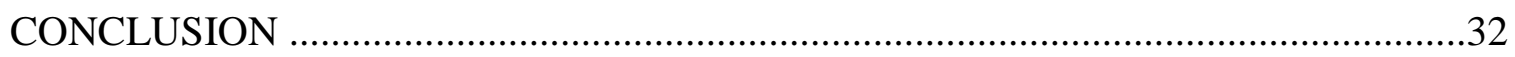

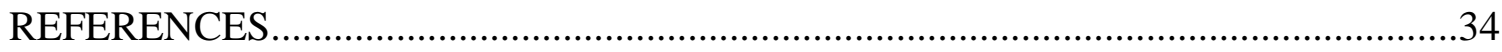

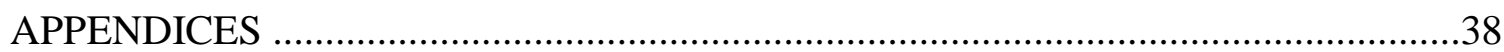

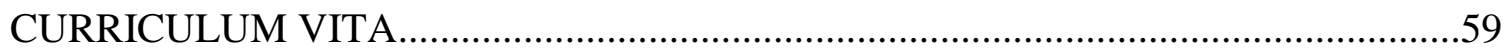




\section{INTRODUCTION}

The purpose of this study is to examine the research on interdisciplinary studies

and how it pertains to UofL's Vision 2020 Plan. A potential joint degree program will be proposed within the individual goals of the College of Education and Human Development and the College of Arts of Sciences.

With consideration of the process of pursuing a joint degree, the cultures of each college will be examined using the Symbolic Convergence Theory to bring these two cultures together for a common goal. In addition, a focus group among current students will be included to provide the student prospective.

This study is necessary because interdisciplinary studies are successfully growing among U.S. universities and it is UofL's goal to endure this growth and success. In addition, it is important for all involved to make this work to recognize differences so that those differences can be brought together or bring in additional faculty who have interdisciplinary backgrounds. This study will ultimately strengthen UofL, not only by helping it reach the goal but also to have colleges working together. It is also an opportunity to see other options beyond those suggested in 2007 when the 2020 Plan was written.

This study makes a unique contribution because bringing colleges together, their willingness to step out of their own culture and make a new one provides additional benefits to the university, to students, to other faculty as well as to prospective students. 


\section{LITERATURE REVIEW}

The following literature review will examine how using the Symbolic Convergence Theory (SCT) along with the development of a rhetorical vision will be a valuable mechanism to pursue a large-scale movement of the creation of a combined degree program. This Fantasy theme concept is the means by which people carry through what is in their mind, make it visible, then share it and shape it into a social knowledge (Bormann, 1982). Olufowote (2006) concurred that specifically using the Fantasy theme Symbolic Convergence Theory (SCT) is particularly useful with organizational communication and analyzing complexities toward collective action.

In 2007, the University of Louisville (UofL) embarked on a 12-year plan called the Vision 2020 Plan (2008-2020), identifying five main goals to move the university toward becoming a top 20 public metropolitan research university (UofL, 2007). These five goals have also been included with UofL's overarching mission statement (UofL, 2015):

\section{UofL Goals and Scorecards}

The University of Louisville shall be a premier, nationally recognized metropolitan research university with a commitment to the liberal arts and sciences and to the intellectual, cultural, and economic development of our diverse communities and citizens through the pursuit of excellence in five interrelated strategic areas:

1. Educational Excellence

2. Research, Creative, and Scholarly Activity

3. Accessibility, Diversity, Equity, and Communication 


\section{Partnerships and Collaborations \\ 5. Institutional Effectiveness of Programs and Services.}

Of the five main goals with the 2020 Plan, one is Educational Excellence which includes interdisciplinary studies and getting ahead of what the future holds for workforce development. Exploring the feasibility of combining degree programs and how that as an option could help UofL reach its goal of Educational Excellence is explored as well as challenges that may be faced as a result of combining degrees particularly when the dual degree programs would be offered from two colleges of the university.

As a part of the 2020 Plan, each college at UofL was charged with devising its own strategic plan to determine what each would do toward reaching the university's five goals. To track the colleges' progress toward those goals, Score Cards were also created for each college (UofL, 2010). The Score Cards essentially provide percentage increase or decrease data to the colleges on an annual basis.

The Score Cards identify job placement for alumni as a goal toward Educational Excellence. The Plan also includes community involvement for UofL as an economic driver to help attract employers to Louisville (UofL, 2007). New employers could in-turn hire UofL graduates and that would provide a positive career outlook for students and improve those scores on the Score Cards. The goal of Educational Excellence could be reached in many ways. One way that UofL has identified is by expanding interdisciplinary studies (UofL, 2007). "Integrated learning supports meaningful learning” (Zhbanova et al, 2010, p. 256). 


\section{Interdisciplinary Expansion}

Expanding interdisciplinary studies has also been a hot topic at many colleges and universities around the country (Sá, 2008). Reportedly, there has been a 250\% increase in college programs adopting interdisciplinary studies over the course of a 25 year period (Goodman \& Huckfeldt, 2014). Goodman and Huckfeldt (2008) proposed that this increase could be attributed to increased student learning outcomes (SLO). Students that have interdisciplinary experiences retain their majors and are better prepared for life and careers (Kezar \& Elrod, 2012). In the study conducted by Zhbanova et al (2010) comparing integrated with single-subject lessons, they found that students do better with interdisciplinary than conventional single-department programs.

Natalle \& Crowe's (2013) assessment of interdisciplinary studies set-out to identify how learning outcome skills would include thinking critically and communicating effectively. They developed a model where literacy (theory, research, and writing) and discipline (communication courses) could be joined to evaluate the SLOs. The model was a mean performance scale on three specific information literacy (research) questions, and a similar model could be used at UofL to assess learning outcomes.

Before embarking on an integrated program, universities must consider organizational structure and the culture of those schools when considering the addition of new degree programs (Borrego et al, 2014, p. 863). Educational reform’s success, particularly with undergraduate majors, is often dependent on the commitment and motivation of faculty (Chen et al, 2009). 
The expansion of interdisciplinary studies can have different interpretations and different approaches. "It is important to understand how people think about interdisciplinarity, enlist support for it among faculty and administrators, and eventually change the university" (Borrego et al, 2014, p. 863). It is also important to gauge student interest so that a viable program will be attractive to a prospective student or to one that may be indecisive about which direction to go based on career paths or interest. Chen et al (2009) explained that interdisciplinary studies - curriculum and instruction - expands student knowledge and improves the quality of the student experience. The student perspective will be explored later.

\section{Mission and Strategies}

For the purpose of this study, the strategic plans for the College of Education and Human Development (CEHD) and the College of Arts and Sciences (A\&S) were reviewed for their individual strategy on the first goal of Educational Excellence. Under Educational Excellence, in the CEHD and A\&S Score Cards, it has increase the number of baccalaureate degrees, with a few subsets of how to accomplish that including (UofL, 2010):

- $\quad$ Decrease student to teacher ratio;

- Increase the number and level of degrees related to Science, Technology, Engineering and Math (STEM); and

- $\quad$ Science and math teacher preparation.

The A\&S Score Card does have the same goals as CEHD for Educational Excellence, but on the last subset (science and math teach preparation), it is stated that A\&S will work with CEHD to achieve that goal. 
From that statement, it is encouraging to see that A\&S already anticipates working with other academic units to reach an important goal. However, what was not apparent in either of the college's goals was to create new degree programs at the undergraduate level. There also was no proposal for creating joint degrees. Presumably combining existing degrees would be more cost-effective than starting a new one from the ground up because most of the curriculum already exists along with faculty to teach it, and administration to manage it. Therefore, fewer new resources should be needed with such a plan.

In the CEHD strategic plan, the college states "adhering to the highest standards of performance in knowledge of content, teaching, leadership, school counseling, educational research, and other relevant professional disciplines, reduce achievement gaps and promote standards-based curricula" (UofL, CEHD, 2007). To achieve Educational Excellence, A\&S has in its strategic plan, "achieve membership in Phi Beta Kappa, reduce student to advisor ratio (200 to 1), increase full-time faculty by $33 \%$ and insure that all A\&S students are provided with the opportunity for study abroad or an international program" (UofL, A\&S, 2007).

In all of UofL's strategic plans, financial resources were outlined to explain what would be needed to achieve their respective goals, so anticipated dollars needed through existing resources or potential development is certainly a consideration. Additionally, one of the reasons interdisciplinary studies have been growing is due to requirements of federal funding agencies (Holley, 2009).

Financial considerations is one of many topics for discussion that should take place when considering a joint degree. Funding is competitive, so this alone could be a 
threat to resources and to positive collaboration (Kezar \& Elrod, 2012 and Stone et al, 2009). “Typically, resources and rewards are directed via a hierarchical organizational structure of departments, schools, and colleges" (Borrego et al, 2014, p. 859). Although the overarching goal as stated in the mission statement is to become a top 20 research university, the university also recognizes that interdisciplinary expansions are not limited to only those fields such as medicine and engineering that generate funds (UofL, 2007).

Other topics that should be discussed are culture, faculty expertise, interdisciplinary background, visions and missions. "Unless all of most members share some fantasies in common ie., unless they have an organizational saga, both the members' commitment to the organization and their ability to create a cooperative communicative climate will be slight" (Bormann, 1982, p.58). For the long-term success of interdisciplinary programs, Stone et al (2009) found they should be integrated into the individual unit's mission allowing 'the program to function within the everyday workings of the institution and lessen marginalization.'

"The mission statement of $\mathrm{A} \& \mathrm{~S}$ is to improve life in the Commonwealth and particularly in the greater Louisville urban area, creating knowledge through its research, sharing knowledge through its teaching, and guiding and all its students to realize their potential.

We believe that an excellent education in the liberal arts and sciences is the best preparation for life and work in a world of increasing diversity and ever-accelerating change because it prepares our graduate to be informed and critical thinkers, creative problem-solvers, and confident communicators.

Our students learn by doing. They conduct research and express their creativity, include ethical considerations in their thinking, and experience the world from the perspectives of their cultures. The college brings the heritage of the intellectual tradition to bear on the challenges of the future" (UofL, A\&S Mission, 2015).

"The mission of the CEHD is to embrace the university's mission as a metropolitan research university committed to advancing the intellectual, cultural, and economic development of our diverse communities and citizens. We promote the highest levels of learning and social, emotional, and physical health and well-being for all 
children, individuals, and families. Our programs enhance the organizations and communities in which they grow and develop.

Our mission is to advance knowledge and understanding across our disciplines and constituencies and to develop educational leaders who will inform policy, improve practice, strengthen communities, and address pressing social concerns. We prepare students to be exemplary professional practitioners and scholars; to generate, use, and disseminate knowledge about teaching, learning, health promotion and disease prevention, and leadership in public and private sector organizations; and to collaborate with others to solve critical human problems in a diverse global community. We seek to continually improve the quality of life for all in our metropolitan community, the Commonwealth of Kentucky, and the nation” (UofL, CEHD Mission, 2015).

Notably, there are similarities in the missions of both colleges but as expected there are defined goals related to advancing the individual college's programs. According to Kezar \& Elrod (2012), "Studies have demonstrated that students with exposure to interdisciplinary learning experiences tend to be retained as majors, as well as gaining preparation for successful careers and life in the 21st century" (p. 17).

To begin the process of starting conversations across the college units, McCoy and Gardner (2012), proposed there are five questions that faculty, administrators and students should ask when looking for collaboration across the campus:

1. Do you have enough time?

2. Do you have the right people?

3. Do you have the right departments?

4. Do you have the right policies?

5. Do you have sufficient resources?

\section{Rhetorical Vision: Working Toward a Common Goal}

McCoy and Gardner (2012) further explained that teamwork is the key to achieving great things such as battling cancer or dealing with environmental tragedies 
and it is no different for interdisciplinary collaboration, which is bringing together at least two different disciplines. Blending specialties from multiple areas can present some challenges and even hindrances. However, Woods' (2006) research on interdisciplinary teaching indicated that there is 'an educational benefit of engaging critically with one's own discipline by viewing its limitations from another perspective and that the need for multi-professional teamwork is increasing due to pressing world challenges.'

What also should be considered is that not all people or programs are suitable for interdisciplinary work and universities should provide the "incentives to conduct the work as well as the resources and time to do it” (McCoy \& Gardner, 2012, p. 48).

As conversations about collaborating begin, Lardner and Malnarich (2009) explain how to get those conversations organized through the work of Veronica BoixMansilla (2009), who was quoted, "Interdisciplinary understanding is the capacity to integrate knowledge and modes of thinking from two or more disciplines in order to produce a cognitive advancement - to explain phenomena, fashion products, solve problems in ways that would have been unviable through a single disciplinary means."

Her recommendation is to use a three-point protocol (Lardner \& Malnarich, 2009, p. 31):

- $\quad$ Get acquainted - get to know each other's discipline and student's work;

- Zooming In - focuses on four elements of interdisciplinary work (purpose of the piece of work, ways the two or more disciplines inform the work, how these areas are integrated and student's reflections of the work); and

- $\quad$ Stepping back - examining the implications for teaching and learning. 
"An economist working on the interdisciplinary project that McCoy and Gardner (2012) were exploring said, "When I first started working with the other social scientists, it took us about six months to get on the same page - and I'm a social scientist!" And an engineer said, "We have to learn each other's languages... when you move into a slightly different field, you have to learn all the background that it includes" (p. 46).

With regard to culture, members must be able to identify a connection to an idea, take ownership and take action (Underation, 2012). "Culture in the communicative context means the sum total of ways of living, organizing, and communing build up in a group of human beings and transmitted to newcomers by means of verbal and nonverbal cues" (Bormann, 1982, p. 50). This concept of merging cultures can also be accomplished through the SCT, a fantasy theory developed by Ernest G. Bormann in 1972 (1982). He described SCT as two separate symbolic worlds that overlap, giving people the opportunity to share common experiences and achieve mutual understanding (Bormann, 1982). "Investigations by Bales (1970) and Bormann (1975) revealed that the basic communicative process by which people experience symbolic convergence is the dynamic process of sharing group fantasies" (Bormann, 1982, p. 51). Bormann (1982) further explains that SCT allows people to come together with the 'meeting of the minds' because of the interpretations of signs and symbols that gives them mutual meaning. A fantasy is not which it implies, a fictional thought or event. The creation of a fantasy theme is the communication phenomenon in which an event has occurred that groups of people can associate with, so much so that very few words would need to be used in order to recount the event -like an inside story or joke -only those within the group would get it. 
Ultimately SCT is the effect of fantasizing to provide meaning, emotion and action (Cragan \& Shields, 1999). From multiple studies, six theoretical assumptions about SCT have been devised (Cragan \& Shields, 1992):

- Meaning, emotion, and motive for action are in the manifest content of a message.

- Reality is created symbolically.

- Fantasy theme chaining creates symbolic convergence that is dramatic in form.

- Fantasy theme analysis is the basic method to capture symbolic reality.

- Fantasy themes occur in and chain-out from all discourse.

- At least three master analogues - righteous, social, and pragmatic compete as alternative explanations of symbolic reality.

Cragan and Shields (1999) also indicated that in their research 'SCT helps capture the symbolic realities of large groups of people.' Essentially if SCT can be used to bring a smaller group of faculty and administrators together to realize a joint degree then the larger group of people -prospective students - can also adopt the reality.

In Preston's (2006) study on intercollegiate competitive debates, he found that by using SCT for large-scale movements such as this one, that ideas, in this case the movement toward incorporating debate into the classroom successfully, can be developed through rhetorical communities and continue to evolve. The rhetorical communities through rhetorical vision chain-out to the larger audience. Olufowote (2006) describes chaining-out as symbols and meaning moving outward from the original setting to the 'publicly shared consciousness.' Underation (2012) said, "In the case of mass 
movements, as fantasy-based plot lines chain out they can create a general group identity, which Bormann called a 'rhetorical vision,' that animates those who are a part of it. To put this another way, meaning is created by the consent of the governed" (p. 286).

The fantasy theme or theory is derived from Bormann's (1982) definition “in which characters enact an incident or a series of incidents in a setting somewhere other than the here-and-now of the people involved in the community episode" (p. 52). In this scenario, the symbols could be construed as the 2020 Plan of what UofL will look like in the future (time frame other than here-and-now) and the other is the future of the students' -where they see themselves one day following graduation.

The fantasy theme is similar to a common vision. The common vision is attained through SCT and creates symbolic realties. These symbolic realties are a rhetorical vision. Rhetorical vision is described by Olufowote (2006) as 'ontological perspectives of humanistic rhetorical approaches and scientific approaches creating symbiosis in two ways: framework and communication as embodying both fantasy and logic.'

"People who share and participate in the rhetorical vision make up a rhetorical community" (Vasquez, 1993, p. 204). Palenchar (2002) says rhetorical vision is made up five structural terms, while Cragan \& Shields (1992) claim rhetorical vision itself is one of six fantasy dramatic structures:

1. Dramatis personae (character, positive or negative human element)

2. Plot lines (action within context)

3. Scenes (where the character enact plots)

4. Sanctioning agents (justification for group's existence/belief in rhetorical vision)

5. Master analogues (value orientations that support competing rhetorical visions) 
Cragan \& Shields (1995) developed the term master analogues stating, "The social master analogue views human connections as the basis for rhetorical vision. The righteous master analogue features beliefs about the right way of acting regardless of economic or social benefits" (Palenchar, 2002, p. 135). In addition, master analogues come in three forms: righteous (the right way to get it done), social (human relations), or pragmatic (practical, whatever it takes to get it done) (Bormann, Cragan \& Shields, 1996). Bormann, Cragan and Shields' (1996) conducted a study where they examined SCT's role in the Cold War. Their examination looked specifically at the rhetorical vision aspect. Through their study they identified the life cycle of rhetorical vision which they defined in three streams: consciousness creating, consciousness raising and consciousness sustaining.

Through this life cycle, SCT was used to explain the shared beliefs, visions and dramatic changes that occurred and influenced two generations of Americans as depicted through historical accounts, speeches, books, public opinions and media (Bormann, Cragan \& Shields, 1996) (Cragan \& Shields, 1992). The three primary rhetorical principles that guided the rhetorical visions of this study were: novelty (visions lose vitality enabling them to continue through generations), explanatory power (visions that are confusing become fantasies that can be shared that seem more plausible), and imitation (boredom with visions are replaced with the familiar) (Bormann, Cragan \& Shields, 1996). The study focused much on Power Politics as politics is what primarily drove the Cold War, moving masses of people into shared visions. 
"SCT provides a characteristic mode of explaining human communication by assuming that human beings are social storytellers who share fantasies to build group consciousness and create social symbolic reality" (Vasquez, 1993, p. 206).

One notable storyteller who used SCT to successfully implement a religious movement was Aimee Semple McPherson. According to Underation (2012), "McPherson is an ideal test case to illustrate the flexibility and usefulness of SCT in small group and in large mass communication setting" (p. 276). To realize SCT in laying the ground work for a potential joint degree, Underation (2012) outlines McPherson's sermons (storytelling) as building blocks on how to seed an idea and grow it within a community:

1. Beyond the present (tell your stories to give people vision)

2. Encourage imagination, develop symbols (capture attention, buzzwords)

3. Positive Change (promote acceptance, be personal, hopeful)

4. Productive lives (sense of purpose, encourage action)

5. The Cement: Mass Media (seed communities with messages, ideas, images)

This literature review justifies the means of bringing faculty together and demonstrates that it is possible to pursue the development of a joint degree at UofL. However, bringing faculty together is only one part of the equation, the other is exploring what students think. To find out what students think led to these exploratory research questions:

RQ1: How do students feel about their major?

RQ2: How certain are students about their career path?

RQ3: How do students feel about joint degrees? 


\section{METHOD}

To further explore the feasibility of expanding interdisciplinary studies at UofL a qualitative study was conducted using focus groups with current students. Merely conducting surveys for a quantitative study would only produce the what, but by conducting a qualitative study and examining SCT helps to see the why it is a good idea. Focus group settings are effective for analyzing SCT (Hinnant \& Henrickson, 2014). As mentioned, the missions of the A\&S and CEHD colleges were included to present an example of a potential dual degree, combining coursework from these two colleges. The potential dual degree being examined is a Sport Administration (a department in CEHD) and Communication (a department in A\&S).

These programs were used as an example potential dual degree because the more focused or converged the disciplines, the more status they will have in academe (Ryan \& Neumann, 2013).

Data Collection: Following an Institution Review Board approval, several classes were reached out to for interest in participating in this focus group. This study was conducted in the summertime, so student population as well as faculty was sparse, yielding a more limited group of students. However, after several attempts to recruit students for participation, including face to face and emails, a portion of one SPAD class met for a focus group following class. Ten students agreed to participate, but five actually participated. 
The other focus group conducted was with COMM students. This was a smallersized class and everyone agreed to participate. There were eight students from the COMM class.

Selection: A total of two focus groups were conducted. Students were selected from upper-level classes to ensure major-related coursework had been completed in each of the degree programs. In SPAD, students needed to have completed or be enrolled in a 300-level sports marketing course. In COMM, students needed to have completed or be enrolled in a 300-level strategic communication course.

The focus groups were conducted at lunch time following classes, so food and drinks were brought to provide hospitality, express gratitude for their participation and make sure everyone was comfortable. Students were given an approved informed consent, an explanation was given and confidentiality was assured. In addition, students were told that the focus groups would be audio recorded. Both focus groups were promised the focus group session would last less than one hour and it did.

Description: Thirteen students were involved in the two groups. There were five students from SPAD and eight from COMM. The focus groups were held in separate places on campus and on separate days to ensure there would be no resistance to honesty or disclosure. The students were a mix of male and female as well as black or white, no other races were represented. All students were upper classmen, most students were seniors, but a few were juniors. No demographic information was collected therefore, the ages of students were not identified. 
Interview Guide: A set of five questions was used for each group, several were followed up with probes. The first three questions were the same for both groups, but the last two were slightly different. Depending on the responses, the probes varied.

Focus Group questions asked:

1. What is your current major?

2. What other majors might you have considered? Why?

3. What courses do you wish were offered as a part of your major? Why?

4. [COMM]If you are planning to go into a public relations/communications field, have you thought about what industry you might want to work in? Please explain.

5. [SPAD]Assuming you are planning to work in the sports industry, what type of job do you see yourself doing?

6. [COMM]Has anyone considered working in the sports industry? If so, doing what?

7. [SPAD]Has anyone considered working in public relations? If so, doing what? All recorded focus groups were transcribed. The transcriptions are attached in Appendix E and F. A message analysis was conducted to identify commonalities in the responses of the students to determine validity. 


\section{RESULTS}

From the focus groups, several major commonalities emerged. Indecisiveness of major, pursuing a double major or a minor (feeling their single discipline was limited), uncertainty of job market and interest in SPAD/COMM degree were most common. Other notable responses will be shared.

\section{Current Major and Considered Majors}

When asking the first question, what is your major, all but one COMM student had a COMM major, and that person was majoring in Music but minoring in COMM. In the SPAD focus group, all but one student was a SPAD major, and that person was majoring in COMM but minoring in SPAD. This justified the reasoning behind interviewing upper level classes, that everyone enrolled would have a reason to be there and not just taking an elective. This further implored that these students were true stakeholders in their degree program.

On the second question, what other majors have you considered, all but one COMM major student had indicated being uncertain about what degree to pursue when they started at UofL and had changed majors several times. Additionally, all students interviewed were either double-majoring or were working on a minor or both. Most students indicated they added the additional minor or major because they were "taking classes toward it anyway." The SPAD degree program strongly encourages students to have a minor, though it is not required. If students are taking classes toward other programs and COMM is a recommended minor, this further strengthens the argument to combine the degrees. 
Several students had been in math-related majors before discovering how much they detested math. There were two from SPAD and three from COMM who made the change for the reason of "too much math." Other majors besides engineering, finance and accounting that had been abandoned or added-to as a double major were Teaching, PanAfrican Studies, IT, Spanish and Music. Nearly all of the SPAD students said they majored in that because of its ease.

The responses from the first two questions gave way to the importance of dual degree programs as students felt the need for a back-up in the job market.

In the first two questions, students expressed concern for having only one major in a single discipline without the added major or minor. Both COMM and SPAD students enjoyed what they were studying but felt the single degree program was limiting. The SPAD students felt their program was too limited and should also not be so limiting on sports' curriculum specifically that focus should expand beyond basketball, baseball and football (See Appendix A). In addition, they expressed there was a gap in international focus. The students pointed out there are not only gender differences, but also emphasis on a variety of other sports around the world, and that UofL's program was very U.S.oriented. Soccer was the prime example used as a worldwide popular sport, but not focused on much in UofL's degree program and that they felt was a disadvantage to the university.

\section{Single Discipline Limitations}

Communication majors thought their major was too limited as well, but for a different reason. They felt the communication program was too broad (See Appendix B \& C). Three students felt the degree program should be more focused on aspects of 
communication, such as broadcasting, journalism or public relations. "Our program needs more concentration." Another example of how combining SPAD with COMM could provide COMM with more of a concentration. While most students thought the communication degree would be good to have by itself (two students felt the broader program was better particularly if a student was unsure what direction to pursue), all the students supplemented their communication major with another major or a minor.

By combining these degree programs, the void the students discuss would be eliminated and the coursework outlined in Appendix A-C could be merged. Such classes as marketing, sociology, crisis communication, broadcasting and sports writing are a few examples of good places to start.

When asked what coursework students wished they had as a part of their program, two students from SPAD and three from COMM, said they would like to have broadcasting and more tech-related coursework like video communication or web development. Students indicated this used to be offered in COMM, but is no longer (even though it actually is) while SPAD students said they did not have much tech-related in their coursework at all. Clearly, students were interested in coursework already offered in the COMM program.

A probe was asked at this point about writing in their coursework, if they have had a lot of writing intensive courses or any communication related if non-COMM student. Because writing is needed in any field and it helps with critical thinking (a part of UofL's 2020), the question was asked. SPAD students responded that most of their writing took place in Gen Ed English courses and there was not much, "it was a joke." One SPAD student said that the Ethics course did require more writing. As for 
communication-related coursework, SPAD students said the Gen Ed COMM (i.e., COMM 111, Public Speaking) was all they really had and that writing was not a large part; it was really about presentations or speeches.

On the opposite end, COMM students said they were required to write all the time in just about every class, "but not by choice." Math and writing were two areas that students seemed to have a disdain for and although neither COMM nor SPAD have intense curricula for math, COMM does for writing. Both math and writing help with developing critical thinking skills. One student, had chosen communication as a minor because of all the writing. Academic writing as evidence of disciplinary grounding is one aspect of what Lardner \& Malnarich (2009) looked at with regard to teaching writing courses within interdisciplinary studies, "what is the difference between a 'well-written' paper in psychology and a paper that results from students integrating what they are learning from a composition class and psychology class?" They add, if a science or math-related course is being taught, have students write an essay about the experiment, for example (p. 33).

The final two questions asked were career-related. One was asking what sort of a job they saw themselves in, the other was asking if SPAD students had thought about COMM careers and vice versa. Those questions were followed-up with a question about their thoughts on a SPAD/COMM joint degree.

The SPAD students varied in what jobs they saw themselves going into and still had some uncertainty about which direction they would go:

\section{Career Paths}

"Not sure exactly, anything marketing." 
"Ticket sales or anything marketing."

"I want to be a Sideline Reporter."

"My parents are a teacher and a social worker, so I feel like I'll follow that, probably a teacher and then coach at a high school. I already have a double major so I can't have a minor, too. I might even help organize something at a sports boarding school.”

"I would like to organize events for sports or recruiting."

"I want to do facility management for a major multi-center facility, not just sports but for all events. Then, later on I just want to do field maintenance, mow grass and paint lines."

The COMM group had several students that were unsure and thought having an internship would help them decide whether they liked a particular industry:

\section{Internships}

"I have no idea, not sure."

"TV, but not on, I want to be behind the scenes. I am really interested in broadcasting." "I'd like to go into public relations or international relations. I am going to be studying abroad in Spain."

"I did an intern at a radio station. I decided against that, so I'm not really sure." "I think I'd like to do something, some kind of communications in human resources." "I may want to do something in radio. I am really interested in podcasts." "I did an internship with the Urban Expo doing tweets and stuff. I think promoting events or things would be pretty good."

The aforementioned responses indicate strong marketing interest (marketing, recruiting, promoting) which is threaded throughout the COMM curriculum. The responses also showed some overlap between sports, communication and marketing. 
Both the COMM and SPAD programs include marketing-related courses. The content of those courses could also be considered for combining so that a potential SPAD/COMM major could take one as a requirement instead of two. Syllabi would need to be reviewed, revised and combined to make the course relevant to both programs.

Both groups wanted more internship opportunities. Based on these responses, it is obvious that most students may have an idea of a field but not completely sure what they want to do. Internships do seem to help them figure out what they like or dislike and one student did not know internship opportunities were even available, so that student gained some knowledge from this focus group experience and was planning to look into internships. For the sports industry, internships are competitive, but a necessity and many hire their interns (Belzer, 2014). Another dimension related to a shared fantasy is that for both groups an internship, which suggests practical, on-the-job learning, is important and something they would like to have in their educational experience.

The discussion of jobs segued to gauging the attitudes of SPAD/COMM as a combined degree program. Three students from each focus group indicated they would have selected that major had it been an option. Two of the COMM students said they were debating on SPAD as a major at one time, but did not want to switch majors again and one said, "I didn't know you could minor in it." Students from both programs talked about their interest in sports, whether they like them in general or if they also play them. Cleary, based on these two groups, a significant interest in the combined degree exists.

\section{Growth of the Programs and Industry}

According to Belzer (2014), "Projected to grow $\$ 145.3$ billion between 20102015, the sports industry is flourishing with opportunities in all areas including: sports 
marketing and sponsorship, sports media (traditional and social media), sports facilities and even higher education institutions which are growing at faster than average projected rate of 15\%." This kind of growth certainly shows where the jobs are whether a student wants to do behind the scenes broadcasting or work in human resources. According to Brian Clapp (2015), there are many colleges offering Sports Management and this can set a job candidate apart.

Students were also asked about their academic experience with social media. Students from both programs had touched on social media but had not had in-depth studies to learn how to get it started, how to grow a following and how to make things go viral. Their experience was mostly limited to their personal social media pages. Based on the responses of limited academic coursework with social media, this is an area that could be considered because athletic and communication jobs use this medium heavily.

With nearly 90,000 communication graduates nationwide each year (College Factual, 2013) and the Sport Management degree program growing from three to 300 in a 30 year period (Belzer, 2014), these two programs have a great potential for admissions growth. This dual degree would also make UofL's program stand-out among the SPADonly and COMM-only programs at other universities. There a number of universities offering a Sports Communication program (Start Class, 2015). Among them are University of Texas, University of Evansville, Oklahoma State and Clemson University. Clemson began the pursuit of this degree in 2012 (Clemson, 2012) and claims their program offers a "strong theoretical foundation" (Clemson, 2015).

"When choosing a college where you can pursue your dream of earning a Sports Management degree, the first thing to remember is that all schools are not created equal. 
There is an overwhelming plethora of programs that claim to offer some sort of degree or certification in Sports Management or a related field, but only the right programs at the right institutions can actually be of benefit by giving its students the requisite skills, experiences, internships, and information that are valuable in the eyes of the top sports employers (Fontenot, 2014). Further strengthening the programs is accreditation. SPAD is accredited by the Commission on Sport Management Accreditation (NAACM, 2015) and programmatic accreditation could not be found for COMM, so the pursuit of this programmatic accreditation would be recommended. Promotion of these accreditations could be used in marketing efforts for admissions.

The opportunities mentioned above further validates the promise of a combined SPAD/COMM degree program. From a workforce development standpoint, a student that earns a COMM degree may be able to find a job in the sports industry and a student that earns a SPAD degree may be able to find a job in the sports industry, but if a student had a combined degree, the ability to find a job would likely increase because the graduate has formal training in both programs, making him/her a stronger candidate. For example, KeJuan Wilkins, who earned a degree in Sports Management and Communication at the University of Michigan, is currently the senior communications director for Nike (University of Michigan, 2015).

Their responses also showed interest in organizing events. If a COMM student is taking an events course, for example, the course likely covers the logistics of a special event for a company such as a ribbon-cutting or a major announcement, something more public relations oriented with a highly-defined audience. If a SPAD student is taking an event course, it may cover how to promote or roll-out a sporting event, also a defined 
audience, but perhaps much larger. While there are similarities (such as the need for media coverage) on how to coordinate both, there are some differences that limited coursework may not explain and may not translate depending on the kind of event to be held. This area could be combined to further benefit students and make their career options broader. Though he was referencing joint master's degree programs, in the following statement, the same would be true for undergraduate degree programs. According to the Father of Public Relations Edward L. Bernays, APR (1979), "A public relations practitioner in the complex world not only needs to be a professional who can apply the findings of the social sciences to problems of adjustment and human understanding. He also needs expertise in the field he is advising and consulting with" (p.13).

The students in these focus groups formed a rhetorical vision for a combined degree program. This rhetorical vision was not created consciously, however, but more likely by this unique opportunity to share their thoughts on what they now know they have in common - indecisiveness, uncertainty and interests - a group consciousness. The consciousness creating, raising and sustaining phases of communication with these focus groups will be discussed. 


\section{DISCUSSION}

SCT is defined by Bormann (1982) as bringing two or more worlds together toward a same goal or vision and then bringing that shared vision to a larger group (audience). This study has looked at several layers of SCT at work. "Because SCT is a general communication theory, it can be used to improve communication, as well as assess it (Cragan \& Shields, 1992, p. 205). The first two groups to bring together are the faculty from two different colleges at the university. The third group to bring into this shared culture and shared fantasy/vision is the current students from each of those colleges. The students in the focus groups did not initially recognize they had a shared vision. The focus group sessions helped to consciously create a rhetorical vision among the current students because their shared feelings were brought to light. Participation in the focus groups helped to uncover this existing rhetorical vision when the students openly shared their experiences and identified all the things they have in common. The students discovered this commonality as they shared their thoughts on their indecisiveness with majors as new students and what other programs they should tie-in to make their education more complete as well as their personal interests that could all make their college experience more rewarding.

When the students talked about changing majors, they began looking for courses that not only interested them but also for a major that would be easy to complete. If this dual major was offered, the students would be challenged because of the addition of curriculum but also more motivated because of interest. Prospective students were not included in the study for two reasons. The first is that non-UofL students would not have the ability to have similar experiences as current students and an additional commitment 
of time would be required for those students who may be visiting the university for the first time and already have a full admissions day planned.

In Cragan and Shields (1992) study of SCT use in organizational strategic planning, they explained that for a fantasy theme to chain out and a rhetorical vision to evolve, there must be group consciousness, without this, no rhetorical vision exists (See Appendix D). To an extent, the SPAD students share the culture with the SPAD (CEHD) faculty, and the COMM students with the COMM (A\&S) faculty. For more than two and one half decades, SCT has had a significant impact on communication scholarship and it is particularly useful with organizational communication (Olufowote, 2006). Once the students in the focus groups recognized a group consciousness, the research indicates that a rhetorical vision does exist and the results are that feasibility for a joint SPAD and COMM degree program also exists.

Though the faculty and current students have an existing shared culture, the current students can provide insight on how they (and a prospective student) go about selecting a major, what their interests are, how to settle on a major and where they hope to go with their careers. The student insight provides a look at how a prospective student might consider a SPAD/COMM major and the university can, in-turn, decide how it would market to that future student. The final group to bring into this shared vision then is the prospective students, a new, larger audience that the university, CEHD, and A\&S would need to capture and convert into this culture. From the focus group insights, this is an example of the consciousness raising phase of communication. The current students individual responses spawned a chaining to the larger group which further enhanced the rhetorical vision. This type of communication continues the raising phase of rhetorical 
vision by laying the groundwork for a growing mass, also known as a critical mass. It is called the critical mass of a population because it is this mass of the population that takes the issues at hand and makes sense of them, recognizes their common problems to share fantasies/vision and knows how to or wants to make this vision appealing to others (Bormann, Cragan \& Shields, 1996).

In The 2020 Plan, UofL states that it wants UofL to be the first choice of students 'who wish to excel in the classroom and in life' (UofL, 2007). Interestingly, the symbolic convergence theory is also employed in attracting prospective students. According to Agozzino (2008), through SCT symbols - setting, characters, and action - sports messaging is used to attract prospective students. This demonstrates that sports are important to people, whether they are interested in spectating, participating, or majoring. Consequently, whether a student plans to major in something sports-related, sports are used to attract a student to the university. The students in both focus groups expressed their interest in sports, supporting this idea.

A recent survey conducted by UofL with its employees and published on its website (www.louisville.edu), stated that even the faculty and staff are enthusiastic about UofL's athletics, joining the ACC and the heightened visibility it provides to the university. With the enthusiasm surrounding sports, it would be recommended that the proposed dual degree program use the Sport Administration first in its title: Sport Administration-Communication (SPAD/COMM).

Analyzing the rhetoric of admissions messaging is best done through the framework of symbolic convergence as found in the research by John Stone in 2002 
which evaluated the symbols that colleges used to attract prospective students (Agozzino, 2008).

Additionally, when the symbolic convergence theory is broken down into its three parts - - scene, character and, action -- it is easy to see how this relates to UofL goals. The scene is, of course, the university campus or even the athletic settings, such as arenas, fields, etc (Agozzino, 2008). The scene can also be the SPAD degree program. If this program were to be combined with COMM, it would only expand the interest. The characters are the faculty and students, both current and prospective. And, the action is getting those students to visualize what their future holds, whether watching, playing or majoring in sports, and enroll (Agozzino, 2008).

Future studies on this topic could include focus groups with faculty to provide insight on academic and interdisciplinary studies and what they see as viable dual degree programs and why as well as how they feel certain dual degrees, if any, fit into the priorities of the university. It is important to point out that both programs are interdisciplinary in nature and may explain why these programs are found under the umbrella of a number of different colleges that varies at many universities. Both COMM and SPAD programs have been listed as programs within individual colleges ranging from business to humanities to kinesiology.

By providing an analysis on the syllabi and coursework and the curriculum within that, faculty could also provide insight on the potential of a dual degree in SPAD/COMM, both the pros and cons of trying to put such a degree program together as well as what some of the benefits to students would be. 
One limitation of this study could be the researcher. Because focus groups are somewhat subjective in their interpretations, another researcher may glean a different perspective. In addition, another researcher could use something other than a fantasy theory changing the dynamic of this argument.

Another limitation was the review of all programs currently offered at the university. It is possible and highly likely that there are other programs that could be combined to make a successful degree program benefiting both the university and the prospective student. This limitation accentuates the third phase of rhetorical vision, consciousness sustaining communication. Consciousness-sustaining communication, arguably the most difficult challenge, is effectively keeping that rhetorical vision intact with a continuum from those who originally created and shared the vision to future players in this fantasy dramatic structure of combining the SPAD program with COMM. The master analogue structure of this vision is defined as pragmatic, in that the development of the SPAD/COMM program would be a vision made into a reality because of its practicality and the willingness to do whatever it takes to make it happen

The final limitation was the size and scope of focus groups. Only conducting two did not exhaust the opinion of student or reach redundancy. . 


\section{CONCLUSION}

Interdisciplinary studies is a hot topic and is growing at colleges and universities across the country. The extensive research that has been conducted illustrates that interdisciplinary studies provide not only a broader education creating multiple career paths to follow but also better learning outcomes, making it a worthwhile and attainable goal for UofL. The creation of dual degrees is certainly not the only option for attaining interdisciplinary studies and Educational Excellence, but is certainly worth consideration.

This research conducted exemplifies that creating a dual degree program with SPAD and COMM is a feasible enterprise. SCT is a communicative theory that can be used for analysis of this program as well as future combined programs. SPAD and COMM is just one example. The student focus groups provided valid reasons at the front end as a new student deciding what to study and on the back end deciding what career path to take following graduation. Nearly half the students interviewed found this particular dual degree appealing. An increased number of participants, could result in a greater interest.

In addition, there are many jobs in the sports industry, but SPAD courses alone may not make a graduate qualified for all the different roles. The dual degree could also provide UofL with additional leverage to prospective students giving it an edge over other universities.

While getting the faculty to work together on this type of enterprise can present challenges, ultimately the university must always be thinking ahead to keep attracting students while staying on track with their goals. There are many college choices students have to choose from, so making UofL more competitive with expanded options of degree 
programs should be at the forefront. Continuously growing the student population will also have a positive impact on the financials.

Adding this dual degree could also help in contributing to UofL's goal of Educational Excellence by increasing baccalaureate graduation rates and also improving the job placement rates, with jobs in their fields of study, of course. Next steps should include faculty meeting with other faculty and presenting the idea to administrators.

Using SCT to bring the faculty from institutional boundaries together, then getting current students on-board, and finally attracting future students makes SCT a useful tool to keep moving UofL forward and scoring high on the Vision 2020 Score Cards. 


\section{REFERENCES}

Agozzino, Alisa. (2008). Conference Papers, National Communication Association, 2008, 1-25

Belzer, Jason. (2014). Sports Industry 101: Breaking Into The Business Of Sports. Forbes. http://www.forbes.com/sites/jasonbelzer/2014/02/05/sports-industry-101breaking-into-the-business-of-sports/ Retrieved 01/19/15

Bernays, Bernard L. (1979). Needed: A New Master's Degree. Public Relations Quarterly, Vol. 24 (Issue 2), p. 13.

Bormann, Ernest G. (1982). Colloquy I. Fantasy and Rhetorical Vision: Ten Years Later. Quarterly Journal of Speech, 68, 288-305.

Bormann, Ernest G. (1982). Pedagogic Space: A Strategy for Teaching Discussion Speech Teacher, 19, Issue 4, 272-277.

Bormann, Ernest G. (1982). The Symbolic Convergence Theory of Communication: Applications and Implications for Teachers and Consultants. Journal of Applied Communication Research, 10, 50-61.

Bormann, Ernest G., Cragan, John F. and Shields, Donald C. (1996). An Expansion of the Rhetorical Vision Component of the Symbolic Convergence Theory: The Cold War Paradigm Case. Communication Monographs, 63, 1-29.

Borrego, Maura, Boden, Daniel and Newswander, Lynita K. (2014). Sustained Change: Institutionalizing Interdisciplinary Graduate Education. The Journal of Higher Education, 86, No. 6, 858-885.

Chen, Sufen, Hsu, Ian and Wu, Chien-Ming (2009). Evaluation of undergraduate Curriculum for Interdisciplinary Learning. Teaching in Higher Education, 14, No. $2,161-173$.

Clapp, Brian (November 16, 2015) Why a Sports Management Degree Will Separate you From the Competition http://www.workinsports.com/blog/why-a-sportsmanagement-degree-will-separate-you-from-the-competition/ Retrieved 12/03/15.

Clemson University, Sport Communication Degree (Bachelor of Arts) http://www.clemson.edu/degrees/sportscommunication?utm_source=search\&utm_campaign=degrees\&utm_medium=1 Retrieved 12/03/15. 
Clemson University, College of Architecture, Arts and Humanities (May 1, 2012) http://www.che.sc.gov/CHE_Docs/academicaffairs/acap/acap-07-12-2012/1e.pdf Retrieved 12/03/15

College Factual (2013). Communication and Journalism. http://www.collegefactual.com/majors/communication-journalismmedia/rankings/most-popular/\# Retrieved 07/06/15

Cragan, John F. and Shields, Donald C. (1992). The Use of Symbolic Convergence Theory in Corporate Strategic Planning: A Case Study. Journal of Applied Communication Research, 20, 199-218.

Cragan, John F. and Shields, Donald C. (1999). Translating Scholarship into Practice: Communication Studies Reflecting the Value of Theory-Based Research to Everyday Life. Journal of Applied Communication Research, 27, 92-106.

Fontenot, Albert. (2014). Top 24 Best Sports Management Degree Programs 2014 http://www.sports-management-degrees.com/best-sports-management-degreeprograms-2014/ Retrieved 01/19/15

Goodman, Barbara E. and Huckfeldt, Vaughn E. (2014). The Rise and Fall of a Required Interdisciplinary Course: Lessons Learned. Innovative Higher Education, 39, 7588 .

Hinnant, Amanda and Hendrickson, Elizabeth Myers (2014). Negotiating Normalcy in Celebrity Health Behavior: A Focus Group Analysis. Journal of Magazine \& New Media Research, 15, 1-20.

Holley, Karri A. (2009). Interdisciplinary Strategies as Transformative Change in Higher Education. Innovative Higher Education, 34, 331-344.

Kezar, Adrianna and Elrod, Susan (2012). Facilitating Interdisciplinary Learning Lessons from Project Kaleidoscope. Change, 16-25

Lardner, Emily and Malnarich, Gillies (2009). When Faculty Assess Integrative Learning: Faculty Inquiry to Improve Learning Community Practice. Change, 28-37.

McCoy, Shannon K. and Gardner, Susan K. (2012). Interdisciplinary Collaboration on Campus: Five Questions. Change, 44-49.

Natalle, Elizabeth J. and Crowe, Kathryn M. (2013). Information Literacy and Communication Research: A Case Study on Interdisciplinary Assessment. Communication Education, 62, 97-104. 
North American Society for Sport Management (NASSM): www.nassm.com Retrieved 01/19/15.

Olufowote, James O. (2006). Rousing and Redirecting a Sleeping Giant. Management Communication Quarterly, 19, 451-492.

Palenchar, Michael J. and Heath, Robert L. (2002). Another Part of the Risk Communication Model: Analysis of Communication Processes and Message Content. Journal of Public Relations Research, 14, 127-158.

Preston, Jr., C. Thomas (2006). Debating About Debate: A Symbolic Convergence Theory Meta-Analysis of Educational Reform Movements in Intercollegiate Debate. The Forensic of Pi Kappa Delta, 91, 15-26.

Ryan, Suzanne and Neumann, Ruth (2013). Interdisciplinarity in an Era of New Public Management: A Case Study of Graduate Business Schools. Studies in Higher Education, 38, 192-206.

Sa', Creso M. (2008). 'Interdisciplinary Strategies' in U.S. Research Universities. Higher Education, 55, 537-552.

Stone, Tammy, Bollard, Kathleen and Harbor, Jonathan M. (2009). Launching Interdisciplinary Programs as College Signature Areas: An Example. Innovative Higher Education, 34, 321-329.

Start Class (2015). 2015 Best Colleges Offering Sports Communication Degrees. http://colleges.startclass.com/d/o/Sports-Communication Retrieved 12/03/15.

Underation, Chris (2012). Seeding the Vision: Symbolic Convergence Theory and Aimee Semple McPherson. Atlanta Journal of Communication, 20, 274-289.

University of Louisville (2007). The Vision 2020 Plan. http://louisville.edu/president/vision2020.pdf Retrieved 06/22/15

University of Louisville (Created 2010, Updated 2014). 2020 Plan Scorecards http://louisville.edu/provost/planning/scorecards Retrieved 06/22/15

University of Louisville, Communication Degrees (Bachelor of Science and Bachelor of Arts). http://comm.louisville.edu/department/degrees.php Retrieved 07/21/15.

University of Louisville, Sport Administration Curriculum (Bachelor of Science). http://louisville.edu/education/degrees/files/bs-spad.pdf Retrieved 07/21/15.

University of Louisville, Mission Statement. http://louisville.edu/about/ Retrieved $06 / 22 / 15$ 
University of Louisville, CEHD Strategic Plan (2007).

http://louisville.edu/education/about/conceptualframework.pdf Retrieved 06/23/15

University of Louisville, A\&S Strategic Plan (2007).

http://louisville.edu/artsandsciences/faculty-staff/files/AS_Strategic_Plan_20072020.pdf Retrieved 06/23/15

University of Louisville, A\&S Mission Statement

http://louisville.edu/artsandsciences/about/mission Retrieved 07/04/15

University of Louisville, CEHD Mission Statement http://louisville.edu/education/about $\underline{\text { Retrieved 07/04/15 }}$

University of Michigan, School of Kinesiology Sport Management Advisory Board http://www.kines.umich.edu/academics/undergraduate-programs/sportmanagement/sport-management-advisory-board Retrieved 12/03/15

Vasquez, Gabriel M. (1993). A Homo Narrans Paradigm for Public Relations: Combining Bormann's Symbolic Convergence Theory and Grunig's Situational Theory of Publics. Journal of Public Relations Research, 5, 201-216.

Woods, Charlotte (2007). Researching and Developing Interdisciplinary Teaching: Towards a Conceptual Framework for Classroom Communication. Higher Education, 54, 853-866.

Zhbanova, Ksenia S., Rule, Audrey C., Montgomery, Sarah E., and Nielsen, Lynn E. (2010). Defining the Difference: Comparing Integrated and Traditional SingleSubject Lessons. Early Childhood Education, 38, 251-258. 
Appendix A

Bachelor of Science Sport Administration Curriculum

General Education Hours General Education Requirements 34

Programmatic Requirements Hours HSS 181 Total: 6

Academic Orientation 1

HSS 101-167 Physical Education Activity Courses 2

HSS 184 Healthy Lifestyles I OR HSS 310, Healthy Lifestyles II OR HSS 293 Social \&

Psyc Aspects of Physical Activity 3

Admission Courses in Sport Administration Hours Total: 6

SPAD 281 Principles of Sport Administration 3

SPAD 284 Issues and Ethics in Sport 3

Core Courses in Sport Administration Hours Total: 33

SPAD 382 Organizational Behavior in Sport 3

SPAD 383 Sport Marketing 3

SPAD 390 Sport Governance 3

SPAD 391 Sociology of Sport 3

SPAD 401 Career Development in Sport Administration 1

SPAD 402 Internship in Sport Administration 8

SPAD 404 Financial Principles in Sport 3

SPAD 405 Sport Facility Management 3

SPAD 489 Legal Aspects of Sport 3

SPAD 490 Senior Seminar in Sport Business 3

SPAD Electives Hours Choose 9 hours of SPAD electives Total: 44

SPAD 360 Administration of Intramural Activities

SPAD 480 Athletics in Higher Education

SPAD 509 International Sport

SPAD 524 Management of Professional Baseball

SPAD 525 Sport Event Management

SPAD 529 Women and Sport

SPAD 530 Sport Promotion and Sales

SPAD 536 Non-Profit Sport

SPAD 545 Sport Communication

SPAD 561 Special Topics in Sport Administration

SPAD 571 Sport for Development and Peace Entrepreneurship

Electives (consult advisor) 35

Minimum Total 123 


\section{Appendix B \\ Bachelor of Science Communication Curriculum}

General Education

Arts \& Sciences Programmatic Requirements

Modes of Inquiry

Humanities or Natural Sciences Electives - 300+

Foreign Language

Department of Communication

Communication 201, 303, 304, 305, 315, 316,

417

Communication 302 or 319

Communication 320, 323, 345, or 348

Communication Electives - 300+

Communication Electives - 400+

Supporting Courses

Statistics Course

Social Science Electives

(12 hours in addition to Gen Ed courses)

Natural Sciences (not Mathematics)
34 hours

13-15 hours

1 hour

6 hours

6-8 hours

48 hours

21 hours

3 hours

3 hours

15 hours

6 hours

18 hours

3 hours

12 hours

3 hours

Free Electives

6-8 hours

Total

121 hours 
Appendix C

Bachelor of Arts Communication Curriculum

General Education

34 hours

Arts \& Sciences Programmatic Requirements

19 hours

Modes of Inquiry

hour

Humanities or Natural Sciences Electives - 300+ 6 hours

Foreign Language

12 hours

Department of Communication

Communication 201, 303, 304, 305, 315, 316

36 hours

Communication Electives - 300+

18 hours

Communication Electives $-400+$ 12 hours

6 hours

Supporting Courses

Statistics Course

24 hours

Social Science Electives

Social Science Electives - 300+

Natural Sciences (not Mathematics)

3 hours
6 hours
12 hours
3 hours

Free Electives

8 hours

Total

121 hours 
Appendix D

Symbolic Convergence Process

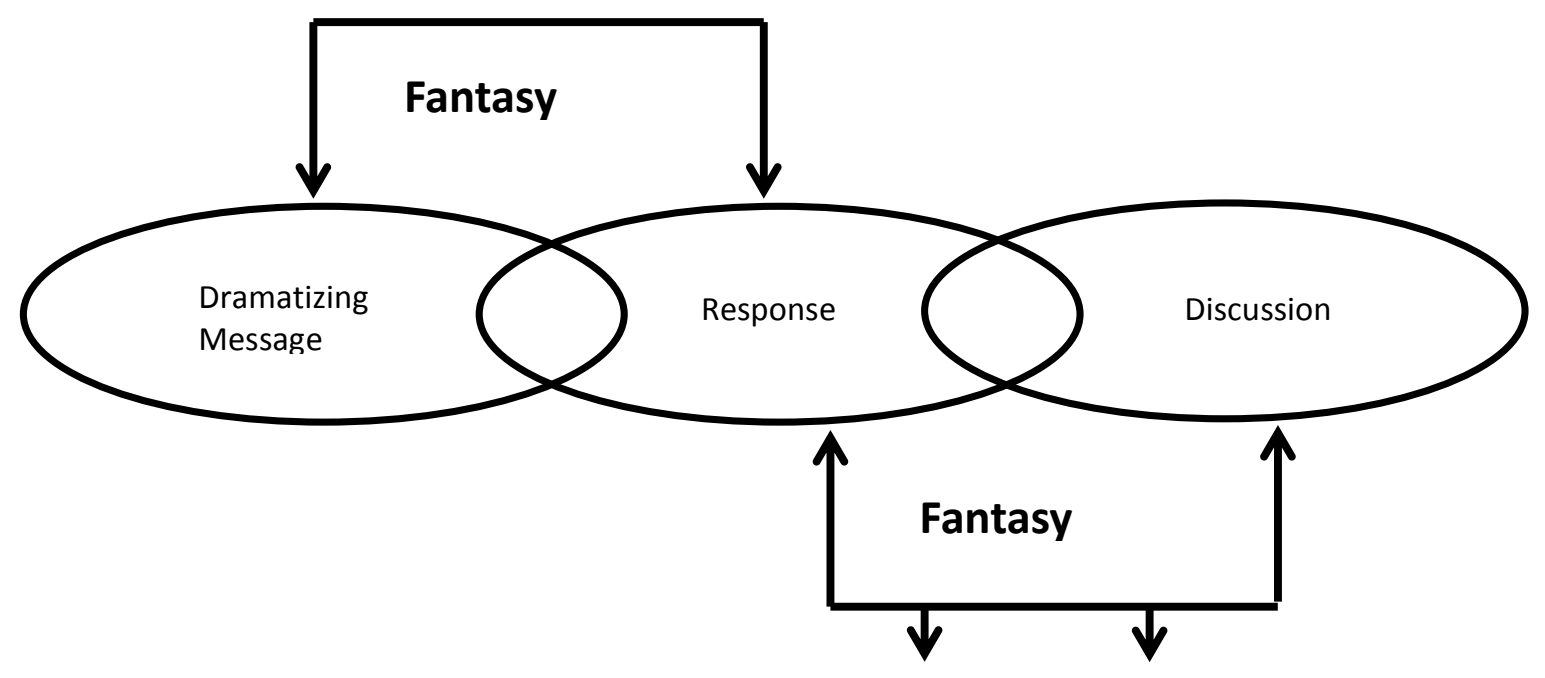

Rhetorical

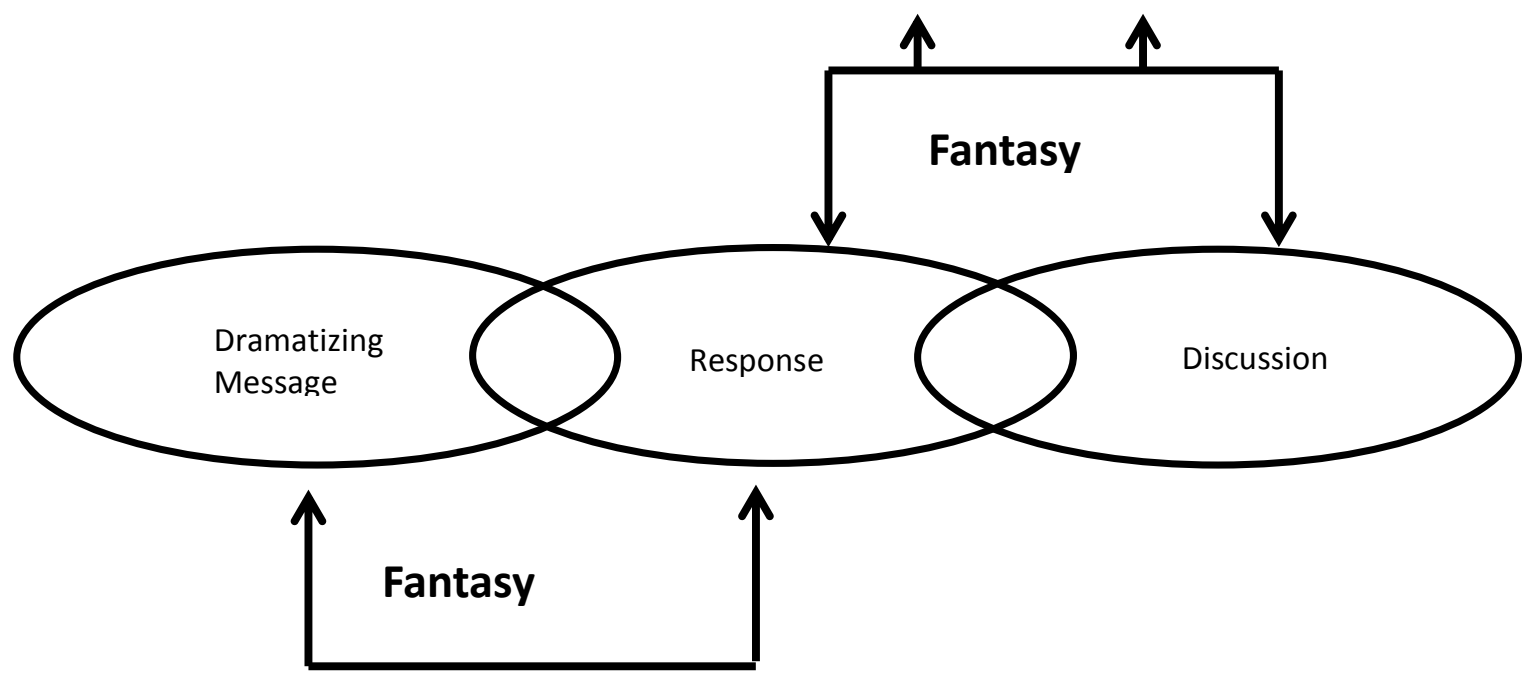




\section{Appendix E \\ SPAD Focus Group Transcript}

[Introduction/Overview of Project/Explanation of Consent Form/Thank students for participating and reminder of confidentiality and voluntary participation/Focus group will be recorded/Any questions about consent form or project]

What is your major?

Student 1- I'm a comm major with a minor in Sports Admin.

Student 2- I'm a double major in exercise science and sports admin.

Student 3- I'm double majoring in sport admin and Pan African Studies.

Student 4- I'm a major in sport admin and a minor in marketing (my advisor recommended this minor)

Student 5- I'm a sports admin major and a forensic science minor.

You guys already seem to have some joint stuff going on --What drew you to this field?

Student 1- Well I want to be a sports broadcaster, they don't have broadcasting here at UofL so I did comm and decided at the end of my sophomore year, beginning of my junior year that I wanted to also implement sport administration in my degree but I didn't have enough time to do a major like a double major so they said I should be able to get sports admin minor pretty easily. That's why I did a minor.

With those of you that have minors, do you find that as a pretty reasonable time commitment or does it feel like two majors or does it feel pretty normal?

Student 1- In my opinion, it's uh, I was looking at some of the business minors I saw one of them was like 40 hours, an extra 40 hours and I know it's going to be kinda hard, but there's plenty of minors you can get done in 2 semesters.

Student 2- I can say it's pretty easy because like once you get done with your major courses and your Gen Eds your stuck with all those electives you have to choose from it's easier just to go ahead and pick something to go ahead and get a minor in. 
Student 3- Well my Pan African Studies major, it was a minor beforehand when I talked to my advisor and my advisor said well you might as well go ahead and get a major in it cause you don't need that many more classes.

How does that work? Does it seem completely different - opposite end of the spectrum with those two majors?

Student 1- Well - yeah kind of, Yeah, I mean you've got the sports and then you've got just like all this with African culture and African American culture. But there will be some classes where there's African American sports and things like that. It's like a brief overview of stuff, not like SPAD where you learn the ins and outs of everything. So it's different in that way.

Student 2- For me it's kind of complicated... because I am from [another country] I am planning on going back. And, I am an athlete. I was only going to stay here for a year and now I'm going to do my whole bachelors. So basically what I want to do is become a teacher but the teaching degree does not transfer back to my country. So I'm doing exercise science, but I have noticed that if I'm going to go home and do another bachelors, to try and do the teaching thing I have to do something extra here so that I can use at high school sports, so I did SPAD as an extra because I just had so many extra credits already that I was just able to do that as an extra major.

Student 3- Honestly I don't know (what drew me to SPAD) [laughter] It was actually funny, I don't know if that's the right word - it was an interesting story. I was planning on doing engineering for like - ever and you know I did like all the math stuff, math tests and then they said ok you can join the engineering program. Then during freshman orientation, I was sitting and waiting on my classes and I was thinking and telling myself I don't want to do engineering. So right there on the spot, I started going through all the majors at UofL... I started going sport administration, I didn't even know if that was a choice. So, I started reading about it, blah, blah, blah and like five minutes later when they said what's your major? I said sports administration. [laughter] So I changed my major in one morning and I've stayed with it ever since. I've never wanted to go back. I have a forensic science minor and that's just...forensic science has always been... I'm not going to say a hobby but it's like been interesting to me. That's more kind of like I don't want to get a job in there, I just think stuff they do is really cool, so I'm kind of wasting the minor. But what she mentioned, it's electives, so you might as well get a degree anyways.

So what year are all of you?

Student 1- I'm a junior 
Student 2- I'll be a senior in the fall

Student 3- This is my first year here, but after the fall I'll have enough to be considered a junior

Student 2 - Yeah, I'll have enough credits after the fall to be a senior

Student 4- Senior

Student 5- Junior

So, this is what everyone decided on, from orientation, you didn't start to pursue other degrees in other fields, this is what you chose and stuck with?

Student 1- Uh, I was starting out sort of in the engineering thing... and then I realized I didn't want to do math and all that [laughter]. But my second interest, I've always loved sports so let me learn more about it... and that's how I got the SPAD major.

Student 2 For me, I was already doing a business/marketing major and then kind of like him I thought more and more about it and I was like I do not want to be in a suit every day [laughter]. This is not me. And, I've always played sports, so I figured I would do that but still that business aspect of it, so I did a marketing minor so it's like ticket sales or any marketing, promotion - anything I'll have that business part of it as well as the sports.

So this class you're in, it counts toward SPAD right, or does it count as both?

Student 2- It's both

Oh it does - I love those, don't you?

My next question is what majors you might have considered, but it sounds like you've already answered that and in some cases made it a minor. What courses do you wish were offered as a part of your major then? And why?

Student 1- Sports broadcasting

Student 2- Yes.

Student 1- I mean we have a video communication class but that's not quite the same thing as sports broadcasting. I wish we had more sports - centered classes in the communication department. As far as I know the only one that I know for sure is sports writing which helps get you on the right track for sports broadcasting but actually being in front of the camera or being a sideline reporter at some of the games you have to be 
like an intern in order to do that. So it would be nice if you could just sign up for the class and get the actual experience there. Cause sometimes, I like I know for me, I mean I don't really have the time to do an internship.

Anybody else?

Student 3- I know for me, this might be kind of obvious, but I would be interested in international sports more. I know that there's like a randomly offered elective in SPAD international sport but it's only offered once a year or something like that. And, I just noticed that literally all we talk about is basketball, baseball, or football. And I don't know anything about them - I don't understand anything about baseball and football. So, and I don't know we just did like a logo thing with different franchises, so like all the names everyone says yeah, sure, but when I hear that name I don't know any of that. And, then I try to bring in a soccer reference and everyone looks at me like --what? I just feel like here there's a lot of people who go into those specific sports, it's really interesting to still to like talk about soccer because no one really knows how big soccer is everywhere in the world because it's not really big here. Stuff like that because I feel like you can take a lot of things from international markets and put into American markets, too, so... I feel like that would be interesting.

Student 4- I feel like it's the future because I feel like soccer is going to get a lot more popular. And, then, now, students from like other countries like that student could have a bigger advantage because they've already been around it. So coming here, soccer's brand new and they can be like oh I already know how to do this.

Student 5- Something else I actually plan on when I graduate my girlfriend is going to teach in Japan. I sort of want to like have a little experience, knowing something about international sports. So, I can maybe go over there and try to get somewhere in the job field cause in Japan they're like baseball is really popular and basketball is actually on the rise too. So I want to get my feet wet here, then take it over there.

Assuming you're planning to work in the sports industry, what type of job do you see yourself doing? I know you said broadcasting. What about the rest of you?

Student 1- Sports management, like for a professional team, preferably baseball.

Student 2- I'm not sure like specifically what I want to do but I said I do want to have anything marketing, anything having to do with promoting.

Student 3- I mean I always just wanted to be a teacher. My dad is a teacher. It was just kind of like, my mom is a social worker so I guess it's just always been implied that I would do something like that. Since I've gotten here I've changed around with majors so much. I mean I started out as physical education then I changed to exercise science then I added sports administration and I've only been here for two years. So now actually this class has made me think a lot about marketing too because all I ever wanted to do was like high school athletics. But now taking those marketing classes I'm having a lot of fun 
just thinking about the things we talked about. So I was actually looking into a marketing minor but with two majors it's not really possible. I would barely make it. Maybe if I took 18 hours during semester then 12 in the summer, but with being an athlete that would be really hard.

With teaching do you think you might also do some coaching as well?

Student 3- Yeah, so like that's what I was going for... coaching, teaching that kind of stuff then like maybe organizing events at the high school that I'm at. Or maybe go to like a sports boarding school. We have that where I could do some recruiting - stuff like that. There's a lot of things that I could technically do, but I am trying to keep my options open by doing as much as I can here because I have four years of scholarship so I may as well just take it.

Student 4- I could see like having one of my kids go to an international soccer boarding school. My dream is to help Team USA in the future by having a kid that's playing soccer [laughter].

So you're a big soccer fan?

Student 4- I'm a really like new big soccer fan, but I jumped into like all teams really quick. I just started probably right before the Men's World Cup kicked off and I've stuck with it since. Going back to the jobs, definitely facility management. To me, it doesn't really matter the team but it does matter the facility. I wouldn't want like I mean I know I'll start off somewhere small. And I don't want to finish somewhere small, but I want something with multi-use for example the Staples Center has two basketball teams, but then it also has WNBA team and also the concerts and everything else. So I would want to work where I can be a part of multiple things. Then there's ice hockey the Kings play there. So whoever runs that place has a lot going on. Then, when I get older I want to do field maintenance for a football team. Like I want to mow grass and paint lines. Student 5- That's like modern gardening.[Laughter]

Student 4- If it paid enough, I would do that first. But it won't so I'll do that when I'm like retired. [Laughter]

So are you going to try and tie-in the forensics thing? If something goes wrong at the facility, will you launch the investigation to see what went wrong and who's guilty?

Student 4- I guess I could do that [laughter]. The forensics was a childhood dream, like what I thought I wanted to do when I was a kid. 
Have any of you considered working in communications or public relations? And if so, doing what?

Student 1- I personally haven't even taken the Gen Ed COMM classes so I really don't know.

Is there a gen ed required for COMM?

All- Yeah.

Student 1- I haven't taken it yet, but I did take a public speaking in high school. I didn't do that well in it. I don't do really well with things like that with a lot of people.

Student 2- I mean the only thing I've taken is that Gen Ed. And all it is basically is four different speeches and the first one is an introduction of yourself and then you have to do an informative then you have to do a persuasion and then argumentative.

Student 3- That's also a COMM 111 and a COMM 201 and that's called Intro to Communication. And I think COMM 201 is an elective or one of the Gen Eds. Yeah cause like I got dual credit for it. So, it wasn't too awful.

Listening to what you're saying you made me think of something else I'd like to ask...I'm curious are you learning in this class or any other classes about social media, like the marketing of it? How to take things and make them go viral?

Student 1- I took a COMM technology class last semester. And pretty much the last month or so of the class we were talking about social media. We even had someone from the social media department here come and lecture on the importance of social media for UofL athletics and how even Snapchat has become big so UofL has their own Snapchat account. Also, how you need to follow media trends in social media aspects of things.

Have all of you had a class that goes over this? Not just how to get it, but to get it out there? So, in this marketing class you are taking, what kind of aspects are you covering? You said you discussed focus groups last week....

Student 1- Well today was like trademarks and branding

Student 2/Student 3- patents, too

Student 3- I feel like in some of the SPAD classes we've touched on social media. I feel like it just always just sort of comes up. Like, oh, by the way you can promote this on social media. But other than that I don't think we cover it that much. We did this one time when we learned about focus groups too. We did like how do you do a survey one of the things was the pros and cons of different types of research. And we had social 
media as a point in there too so we talked about that for maybe five minutes. So it's always just kind of like the other student mentioned.

Student 1-It's just to get the knowledge.

What about writing intensive classes?

Student 1- I think there's a sports writing course. It sounds familiar.

Student 2- In COMM, you had to take a WR class, which are your writing classes. I think at least one of them, maybe both have to be above 300 level. So I took sports writing and news writing for my two.

Student 3- I think there's a Gen Ed, there's two English classes that you have to take. There's a 101 and 102. The second one is more like expressive writing - I don't know, there's like a 15 page paper.

Student 4- Honestly my English 101 class, my teacher, she probably thought she was teaching like a graduate level. Because we were like reading all these articles and everything and some of these articles were very gory. Then you'd have to write a research paper on them. Then my English 102 class was like a joke so... I know they have a bunch of different teachers that teach them.

Student 3- It was the other way around for me... Yeah, my 101 class was the easy one. Then my 102 class I had to write an 18 page paper at the end. In our SPAD classes, so far I've only taken like three. One of them is kind of intro, something about ethics more or less. In sports the second is not really writing intensive, but there's a lot of little like mini one-pagers. Like you write small ones, then you have to write a five page paper then and then another five page paper. So it's not like you really have to research something and then write and think about it for a long time, but they do try in the SPAD program to introduce you to the APA format. So they're trying to make us feel comfortable with that with making us write many papers due almost every week. Many of the papers might be just one page so it's not really hard but it's still...

Student 4- So this is going backward a little bit, but first semester fall I did take a COMM class, I think it was 211 (critical thinking) - I took that and I really liked it. I learned a lot.

Student 5- Mr. Bernstein does a really good job. I have the 284 (SPAD) and he was my teacher. And, it was kind of the same thing where we had all of the smaller papers and then I also, he taught facility management and it was the same thing. So definitely Mr. Bernstein understands the importance of writing, but I am going to say he grades really easily. Like I don't think the two classes I took I don't feel they made me better at writing, I mean I had practice but I had never... I don't think... the only thing they really emphasize is the format and if you do it incorrectly, but other than that. Well he did have 
us go to the writing center, it was required. They would look at our papers. We didn't get a lot of feedback from him. He was really nice with our writing and his grading.

Student 1- I mean I took writing courses, it was just so long ago. It was like my freshman year and I took a break so... But they were quite easy. I didn't take anything hard.

Student 5- Most of our classes have us do presentations at the end of the year, so I guess that kind of has COMM in it. Like public speaking, I think most of my major classes have had at least one presentation at the end of the year. And I know for a fact that the class we're in right now we'll have a presentation at the end of the year.

Student 2- Most COMM classes we don't really have a final-final per se what we have, we usually have a longer paper due or a presentation.

Student 3- I think communication is like... because we talk about branding and like personal brands... it's how you sell yourself because I think I talked about this in 381 which is like the first class you take in SPAD... you talk and sell yourself at all times. If you want a job or if you oversee or implement or whatever you have to communicate branding - I feel like communication would be a big part of that. Cause obviously you're going to have to communicate effectively even if there's no camera around. Whatever you say is going to influence your brand and like I actually feel like that would be good to have more communication in this major especially because we do a lot of writing but like what he said everything's very easy. A lot of people take this major because it's easy too. I feel like it could be a lot harder. It isn't that it can't be complex it's just not really.

Student 4- And I do know that, I mean, none of us have taken it yet but career development is one of the classes for SPAD, my boyfriend is actually taking it now. It's the class before you do your internship. They have to do like elevator pitches and that's the only communications I can come up with for 45 seconds scriptive with what they say by the time the elevator comes down. I mean there are like, I guess in that class they're doing communicating or communication tactics I guess. As far as classes we're taking now I really haven't really come across anything, but...

Student 3- I mean maybe it counts, but we had to do like a one page about how you do an interview. What's it called (other students== Resume)? Yeah, a resume, which is kind of written communication I guess, like presenting yourself too. We have to do those for SPAD.

Wrap-up, Thank student participants

Student 1- And I just want to say honestly if they had that sport admin /comm major, I would have taken it.

Student 2- Me too.

Student 3- Yeah 


\section{Appendix F \\ Communication Focus Group Transcript}

[Introduction/Overview of Project/Explanation of Consent Form/Thank students for participating and reminder of confidentiality and voluntary participation/Focus group will be recorded/Any questions about consent form or project]

What year are all of you?

Student 1 senior

Student 2 senior

Student 3 senior

Student 4 senior

Excellent! So many of you have already had most of the classes then... that's awesome. Before we get started, I want to thank you all again for participating and allowing me to interrupt your class this afternoon and I will try to keep this brief and be mindful of your time.

So I want to go ahead and get started and the first thing to find out is... what is your current major? I know this is a communication class, but some people take them as electives or whatever so...

Student 1-I'm double majoring in COMM/Spanish

\section{Student 2-COMM}

\section{Student 3-COMM}

Everyone's communication majors except you, you're double.

Student 4-I'm not a COMM major. I'm music major.

Oh, you're music - what interested you in taking a COMM class?

Student 4-I don't know [laughter] Um... I wanted to try and get a minor in it, in communications. Or is that something that you thought you might actually try and go into a career field?

Student 4- Maybe as like a fall-back if music doesn't work out, I want to go to grad school for music production so... work with 
Really, ok. Well communication is probably a pretty good tie-in with production actually...

Student 4- I like writing and stuff too though

Maybe you could do jingles for ads [laughter]. So, as seniors, sounds like most of you are, were there other majors that you considered? Did you change majors when you first got started? Were you like I like biology and then thought oooh nevermind.... Did you go through some changes?

Student 1- Yeah... business

Student 2- I was still considering psychology.

So like a second bachelor's then?

Student 2- Yeah

Ok, anybody else?

Student 3- I was in the dental hygiene program but then I dropped out and changed.

Really?

Student 3- I really don't like science that much like I mean it's a good career path and I tried to stay with it and so I went to the career fair and that's how I found out about communications and that's how I did that.

Student 4- And I was a CIS major

CIS, computer information? Mmmhmm

Student 4- Yeah... but I realized there was just too much math

Too much math? [laughter]

Student 4- Yeah, I didn't want to do that much math.

Student 5- I was an accounting major. (Background - oooh, shoo/ew, sighs)

Ok, did you think it was too much math? Or did you have other thoughts?

Student 5- I was okay with the math, it was just all the business part of it, I realized I was just not a business person... the whole I don't know... the whole portfolios... some of the everyday things. 
So you liked the accounting, but maybe not economics or finance or some of the other things?

Student 5- Mmhmm, yeah.

So how have you liked communications?

Student 5- I like it, it's a big change, but I like it.

Student 6- Oh, I was a bio major when I came here, then I was business and now I'm communication.

Ok, so you have the science and the creative...? [laughter].

Student 6- Mmhmm, yeah, I mean I thought about business but then I don't like all that other stuff that goes with it.

What about you?

Student 7- Uh, I had a double major with business and music, but I just really don't like business. I found that out really quick. Plus I took a lot of classes spread over the summer and that was just terrible. So I decided to just major in music and try to get a minor in communications.

Communications, even potentially... for you... have you thought about what industry you might want to work in... where would you want to take your communications degree?

Student 1- No idea. [laughter]

Student 2- I wanna do IT.

You still want to stay in the CIS field with communication?

Student 1 - I know the CIS side was a little too much math, but IT is more of the hardware, but I know with all the communication with all the other stuff you want... you need... to be able to communicate so I want to do all the certifications . That's what I want to do. I know it's kind of weird with a communication degree.

Well communications is a pretty broad degree so there's a lot of places you can go which is why I was interested where you might go with it... if there is particular industry you like or...it sound like you do...

Student 1- I'm like really interested in television. Like not so much being on TV, but just like the background of it, as far as like the network and that sort of thing 
So not a broadcaster, on air... ok.

Student 2- I want to do PR or international relations. I'm not sure... I'm going to internship. I'm going to Spain this fall to finish my degrees out. So we'll see how it goes.

That's what I was going to ask you... if anyone has been considering internships to give you some ideas of what career paths you might want to go into.... You may do an internship and say this is awesome or you may do one and say - Boo, I don't want to go this way. So, you're thinking about doing an internship and going to do a study abroad? Has anyone else thought about doing an internship?

Student 1- I did an internship with the radio stations here 101.3, B96.5 cause I wasn't sure where I wanted to go with communications but I decided radio is not where I want to go.

Ok [laughter], but that's helpful right? To even know - that's not what I thought it was. Have you done any internships? (directing to a particular student)

Student 1- Uh, no, I have not. It's kind of typical to find music internships abroad, here they don't offer much around here. The radio station thing sounds interesting, I didn't know they did that. (other students replying yeah, oh yeah, uh-huh, I had an internship there.)

It might be a good experience it's still tied-in with music... so... (another student states there's about five stations in the whole building, so you can sort of choose). So you're all incoming seniors, you'll be seniors this fall?

Student 1- I'm about to be a junior.

Have you thought about any industries?

Student 1- Well, I've thought about human resources, but I don't know for sure yet.

Oh, internal communications. That's usually what communications is for HR - internal where you communicate with employees and make sure everyone's a happy camper... Make it a great place to work and those kinds of things, they look to the communicators for to help to make everyone love their job - no pressure. [laughter]. You have any thoughts?

Student 2- I want to do radio.

You do like radio?

Student 2- Yeah. 
Have you had any exposure to it?

Student 2- Well not like at a radio station, but I've done like pod casts and stuff like that.

Well that's real important too. What about social media? Have you guys had some training so far in school with just...everybody has twitter and Instagram but...training with how to manipulate it, how to help things go viral, how to get people going and doing a like and how to get people paying attention to what you have to say?

Student 1- I had an internship with Urban Expo, they would have me send out tweets and try to locate people who like certain things, then direct people to the Urban Expo website to tell them they should come.

Student 2- I know there's a class here I took with a professor and all her classes are PR stuff and we talked about all the different stuff that's happened on social media and how to handle social media. It was a really interesting class.

\section{Was it Strat COMM?}

Student 3- Yes, it was Strat COMM.

Was there any other social media classes or any that were more technical? Maybe with analytics? Have you heard of Google Analytics? [A few responses of yes, but no elaboration]

You have to wonder sometimes why did this person get 150 likes on their selfie and someone else got two. What did they do different? Was it just a photo, did they add a byline that caught attention?

What about writing? Have you all taken a lot of writing intensive courses?

Student 1- Yeah, but not by choice. [laughter]

You don't enjoy the writing - is there anyone who does?

Student 2- I like to write. That's one of the reasons I wanted a communication's minor. I'm taking an online news writing class right now.

Did you learn how to write music too?

Student 2- Yeah I mean I kind of learned that myself - I write lyrics and I write music too. And, I've been working on recording things and stuff like that.

That's interesting - sounds like you could have an interesting career path.

Student 2- Thank you. 
Has anyone considered working in the sports industry?

Student 1- No.

Student 2- Yes.

Student 3- I did, but I didn't like changing majors. (laughter)

Student 4- I would like to.

Student 3- I specifically thought about sports administration but I didn't want to change.

Did you think about minoring - did you ask about minoring?

Student 2- I didn't know they had one.

Student 5- If it was combined, I would love that. If I could incorporate IT and the sports that would be really cool.

So, you didn't want to change majors, you've thought about it... but

Student 6- I didn't want to be here longer than four and a half years, so I decided just to do communications.

So does anybody here have minors in anything? I guess you do (directed to comm minor student).

Student 1- I have Spanish and Pan African Studies

So you have two minors?

Student 1- mmhmm.

Oh, ok. And you were double majoring in Spanish (directed to another student). Then directed to both students - do you feel there's some things you could do that's communicating in Spanish possibly?

Student 1- Probably. [laughter]

A few of you have thought about sports, but all of you walked away from it. What year are you this year? (referring back to same student)

Student 1- I'm a senior

So you wouldn't want to add-on the other 18 hours or so to get the minor?

Student 1- I don't want to add-on anything! 
What if you got an offer working in communications say in UofL's communication department doing some sports stuff, do you think that's something you could see yourself doing? And if you did, do you feel you would be adequately prepared? For instance, you've got a coach that does something wrong... or how about basketball player (I won't mention any names) [laughter] you know, crisis communications seems like it would be a pretty good course to take especially if you're working in the sports industry cause there's always something that happens.

Student 1- Yeah, you also got pro sports players coming out doing something like NFL players assaulting women...

Like what I heard last night on BBC news... FIFA - Soccer - they're in the limelight now.

Student 2- Oh yeah.

There's always something. And somebody has to communicate this information and make it sound coherent, make it sound like they still know what they're doing, even if they have a bad apple in the pot. So that's what I'm kind of trying to learn too...

\section{Student 3- Right}

Are there any classes you wish had been offered in this major? Or minor?

Student 1- I think they're broad here. I have some friends, like some of them come from Emerson in Boston and other places and a lot are COMM majors and they're like what's your degree in? I'm like COMM and Spanish. And they're like what in COMM? And I say just communications. It's a broad major. A lot of them have this fixated stuff like my friend had broadcasting communication. Certain things make you pick. I like it here because it's so broad and it lets you go either which way.

This class that you're in - is it required?

Student 1- Yes.

\section{Student 2-Uh-huh.}

Student 3-I would have liked to see more broadcasting. I think it's very broad, the comm department here. In a way it's good but also it's kind of I think not good because it kind of, we almost, we pretty much take what we want to take and there's no specific focus. Know what I'm saying?

So you have a little bit of PR, a little bit of broadcasting a little bit of journalism, a little bit of advertising, but maybe not enough of concentration? 
Student 4- yeah, yeah, right. Instead of just journalism or one of them.

Student 5- Yeah, I would've liked journalism

What about you all?

Student 6- Like they should've had when you first take the comm class a little bit of everything and then like when you want to like she said concentrate in one area, well ok here's certain classes. You don't want to be stuck starting off with for instance, broadcasting and then find out this isn't for me then your credits wouldn't go the right way. If you had a little bit of variety like we have now then wait for your upper level classes so that you can choose. That would be better I think.

What do you all think?

Student 7- I'd like to see more web development classes. Like I took one but I was looking for more they didn't have it.

Student 8- They used to have it, they used to have a second one. I looked it up. Then they took it out. It was just gone. A few years ago. Or something like that.

Student 7- Esrock, he taught some of those.

Are those classes you wish they offered?

Student 1- No, I like them. I like them broad. Yeah, I like that cause when I first came to COMM I didn't know what I wanted to do so kinda taking the different classes helped me. I just wasn't sure which way I wanted to go.

Student 2- I don't know. I don't really like it broad. I like what she said with a broad beginning but then there's different parts to it.

Is there certain areas you like better than others?

Student 3- Uh, not computer stuff. I like the public relations and I want to do management, like business administration and management, but they got rid of that, so...

Student 4- Yeah, they don't have a business management degree anymore.

Student 5- I like it the way it is. Probably because I changed my major so many times so when I came to COMM I got to test out to be able to narrow it down even though I'm still not sure what I want to do but at least it's not like I'm not all the way out there. I don't know, but I wouldn't change it because I don't think I would be able to like pick where I would want to go right now.

Wrap-up. Thank student participants. 
Well, do you all have any questions for me? About this project?

I really appreciate you all participating. And I welcome any questions you may have... It sounds like there could be other good similar opportunities (of joint degrees) with Spanish or Music....

Student 1- I think Spanish would be good.

Student 2- I wouldn't do it but...[laughter]

Well thank you again.

Student 1- I wanted to go back to a question earlier...you asked how we would feel about being qualified in the sports industry... from a communication standpoint, I feel like I would be qualified, but as far as sports background I don't feel I would be qualified. Just because like what I know about sports is pretty limited, so I think it would be good to have some courses introduced to sports administration so I could like speak on it.

You make a good point because you may be able to speak on some of the topics, but if they wanted to know something about the facility like how many people are attending Taylor Swift next week, you may not know that management side. 


\section{CURRICULUM VITA}

NAME:

ADDRESS:

DOB:

Education \& Training:

Professional Societies:
Stephanie Ann French

University of Louisville

Department of Communication

310 Strickler Hall

Louisville, Kentucky 40292

Indianapolis, Indiana - July 20, 1970

Bachelor of Arts, Communication

Jacksonville University, Florida 1988-1993

Public Relations Society of America, past VP, current member

International Association of Business Communications, past VP, former member

Advertising Federation of Louisville, former member

Academic Presentations 